\title{
Geographical variation in the foraging behaviour of the pantropical red-footed booby
}

\author{
Loriane Mendez ${ }^{1,2, *}$, Philippe Borsa ${ }^{3}$, Sebastian $\mathrm{Cruz}^{4}$, Sophie de Grissac ${ }^{1,2}$, \\ Janos Hennicke $^{1,5}$, Joëlle Lallemand ${ }^{1}$, Aurélien Prudor ${ }^{1,2}$, Henri Weimerskirch ${ }^{1,2}$ \\ ${ }^{1}$ Centre d'Etudes Biologiques de Chizé (CEBC), UMR7372 CNRS, Université de La Rochelle, 79360 Villiers-en-Bois, France \\ ${ }^{2}$ UMR 9220 UR CNRS IRD ENTROPIE, Faculté des Sciences et Technologies, Université de la Réunion, \\ 15 avenue René Cassin - CS 92003, 97744 Saint Denis Cedex 9, La Réunion \\ ${ }^{3}$ UMR 250 UR CNRS IRD ENTROPIE, 101 Promenade Roger Laroque, 98848 Nouméa, Nouvelle-Calédonie \\ ${ }^{4}$ Department of Migration and Immuno-ecology, Max Planck Institute for Ornithology, 78315 Radolfzell, Germany \\ ${ }^{5}$ Department of Ecology and Conservation, Institute of Zoology, University of Hamburg, Martin-Luther-King-Platz 3, \\ 20146 Hamburg, Germany
}

\begin{abstract}
While interspecific differences in foraging behaviour have attracted much attention, less is known about how foraging behaviour differs between populations of the same species. Here we compared the foraging strategy of a pantropical seabird, the red-footed booby Sula sula, in 5 populations breeding in contrasted environmental conditions. The foraging strategy strongly differed between sites, from strictly diurnal short trips in Europa Island (Mozambique channel) to long trips including up to 5 nights at sea in Genovesa Island (Galapagos archipelago). The Expectation Maximisation binary Clustering $(\mathrm{EMbC})$ algorithm was used to determine the different behaviours of individuals during their foraging trips (travelling, intensive foraging, resting and relocating). During the day, the activity budget was similar for all the breeding colonies. During the night, birds were primarily on the water, drifting with currents. At all sites, birds similarly performed intensive foraging in zones of area-restricted search (ARS), although the size and duration of ARS zones differed markedly. Red-footed boobies foraged over deep oceanic waters, with chlorophyll a concentrations varying between sites. Birds did not appear to target areas with higher productivity. We suggest that range differences between populations may be linked to other factors such as intra- and interspecific competition.
\end{abstract}

KEY WORDS: Sula sula · Tropical · GPS tracking · Area-restricted search · ARS · Chlorophyll a • Expectation Maximisation binary Clustering $\cdot$ EMbC

\section{INTRODUCTION}

The concept of species-typical behaviour assumes that behavioural traits are common among all members of a species (Greenberg \& Haraway 1998). However, behavioural variation is commonly observed within a species (Lott 1991). While interspecific differences in foraging behaviour are well studied, less is known about how populations of the same species differ in their foraging behaviour.

\footnotetext{
${ }^{*}$ Corresponding author: loriane.mendez@cebc.cnrs.fr
}

Seabirds are 'central-place foragers' during the breeding period, since they nest on land and forage at sea (Orians \& Pearson 1979). Foraging strategies are usually linked to the local environmental conditions (e.g. Sims \& Quayle 1998, Weimerskirch 1998, Burke \& Montevecchi 2009) and vary widely across seabird species (Shealer et al. 2002, Weimerskirch 2007). Some species search for unpredictable resources over wide areas covering large distances during their foraging trips, while others specifically

() The authors 2017. Open Access under Creative Commons by Attribution Licence. Use, distribution and reproduction are unrestricted. Authors and original publication must be credited. 
target oceanographic features such as fronts, shelf edges or sea mounts to find prey (e.g. Schneider 1982, Haney 1986, Weimerskirch 2007, Freeman et al. 2010). These oceanographic features play an essential role in the dispersion and aggregation of nutrients and plankton, which attract both prey and predators. Moreover, it has been found that mesoscale and sub-mesoscale structures (e.g. eddies and filaments) can increase primary productivity and consequently concentrate associated predators such as seabirds (Nel et al. 2001, Weimerskirch et al. 2004, Tew Kai et al. 2009). In tropical oligotrophic waters, resources are scarcer and more heterogeneously distributed compared to temperate and polar waters (Longhurst \& Pauly 1987, Ballance et al. 1997, Weimerskirch 2007). Several species of tropical seabirds feed in close association with sub-surface predators, such as tuna and dolphins, that bring prey to the surface within reach of flying predators (Au \& Pitman 1986, Hebshi et al. 2008).

The red-footed booby Sula sula, hereafter RFB, is a non-migrant seabird species that lives year-round in pantropical regions of the Atlantic, Pacific and Indian Oceans (Nelson 1978). During the breeding season, both partners of the pair take turns between nestguarding and foraging trips. The RFB mainly feeds on flying fishes (Exocoetidae) and flying squids (Ommastrephidae) (Nelson 1978, Schreiber et al. 1996). Since these prey occupy a low trophic position, the chlorophyll a concentration (a common proxy of the water productivity) could be an indicator of their spatial distribution. RFBs appear to target specific areas with higher productivity at some sites (Ballance et al. 1997, Jaquemet et al. 2005, Weimerskirch et al. 2005a) but not at others (Young et al. 2010).

Besides local productivity, competition between individuals may also affect the distribution of the foraging zones around the colonies. Ashmole (1963) described the potential consequences of intraspecific competition on the fitness of central-place foragers like seabirds. He hypothesised that the more individuals a colony hosts, the more the surrounding waters can be locally depleted. This 'Ashmole's halo' (Birt et al. 1987) could lead birds from large colonies to travel further to find resources, inducing a decrease in reproductive success and thus a regulation of the colony size. RFBs breeding in the presence of other tropical booby species could reduce competition by partitioning resources, allowing for coexistence (Lack 1971). As RFBs are known as the most pelagic booby species (Nelson 1978, Schreiber et al. 1996), we expect them to have a longer foraging range in presence of other sulid species.
Few studies have compared the foraging behaviour of a seabird species between different sites to better understand the factors affecting foraging strategies (e.g. Kappes et al. 2011, Oppel et al. 2015). The wide distribution of RFB populations provides the opportunity to examine the influence of contrasted biotic and abiotic conditions from different breeding sites on foraging behaviour. The present study compares the foraging strategies of 5 different populations of RFB in the Indian and Pacific Oceans. Since the breeding sites have contrasting local conditions, we predict that search strategies and foraging parameters will differ between sites up to a certain level, constrained by the morphology and common habits of the species. Knowing that the foraging strategy of the RFB varies substantially between the stages of the breeding cycle (Mendez et al. 2016), we focused our study on the incubation period only.

\section{MATERIALS AND METHODS}

\section{Fieldwork}

Data were collected from 5 sites: Europa Island (EU, Mozambique Channel), Christmas Island (CI, Indian Ocean), Walpole Island (WA) and the Chesterfield Islands ( $\mathrm{CH}$, hereafter 'Chesterfield') off New Caledonia, and Genovesa Island (GEN, Galapagos Archipelago) (Fig. 1). All 5 sites host important breeding colonies of RFBs (Table 1). Our study examined the foraging behaviour of RFBs during the incubation period when male and female alternate on the nest to incubate the egg (Nelson 1978). Timing of field work and numbers of individuals studied in each breeding colony are given in Table 1 . To study the movements of birds at sea, incubating adults were selected randomly and fitted with $20 \mathrm{~g}(32 \times$ $22 \mathrm{~mm}$ ) IGotU GPS loggers (Mobile Action Technology). Depending on the site and date of deployment, locations were recorded every 10, 30, 60, 120 or $300 \mathrm{~s}$. GPS loggers were attached to a group of 3 or 4 central tail feathers using Tesa tape (Wilson et al. 1997). Birds were captured on nests that had been previously identified and mapped. They were marked on the tail or the breast with labile dye to identify the individual rapidly and from a distance. Individuals were captured by hand or, for birds nesting higher in the trees, with a $6 \mathrm{~m}$ telescopic fishing pole fitted with a nylon noose. In a few cases, both partners at the same nest were fitted with GPS loggers. Birds were weighed in a bag with a spring balance, at both the deployment and the retrieval of the GPS 


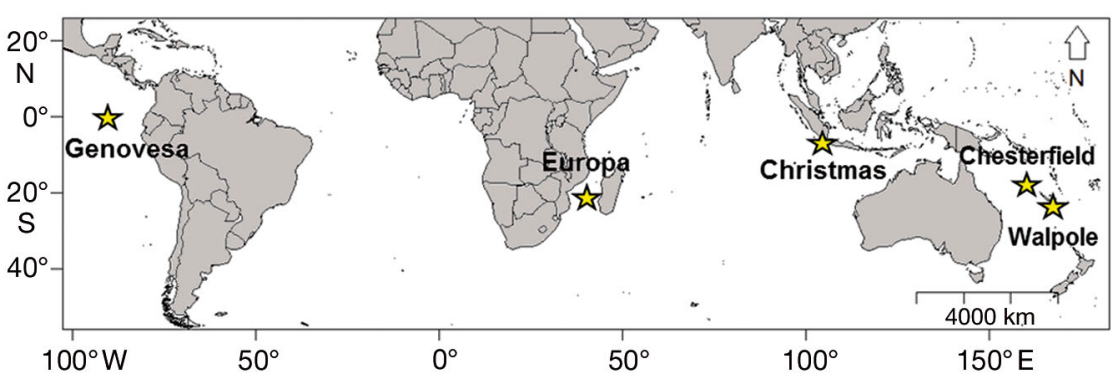

Fig. 1. Locations of the 5 breeding colonies (yellow stars) of red-footed boobies Sula sula studied during incubation

logger to determine gain or loss of weight. The study birds were also measured (culmen height and length, wing length) at the recovery of the GPS logger. Birds were sexed by their voice when possible (males have a higher pitched voice than females; Nelson 1978) or by measurements (females are larger than males; Nelson 1978, Weimerskirch et al. 2006). Blood samples were also collected from a sub-sample of 15 individuals in Europa in 2003 to verify the sex using molecular markers (Weimerskirch et al. 2006).

\section{Track parameters and behaviour labelling}

A total of 199 tracks of birds leaving the island to go to the sea were analysed (Table 1). These tracks represented 1 to 8 successive foraging trips of 123 birds. Complete tracks were defined as trips for which GPS data were available from the departure of the bird from the nest to its return (90\% of the dataset). Incomplete tracks, e.g. due to battery failure of the
GPS device, were used only to estimate specific parameters when at least the beginning of the return phase of the foraging trip was present. Duration of the foraging trip (h), total distance covered $(\mathrm{km})$ and maximum range from the colony $(\mathrm{km})$ were calculated for each track.

To determine the different behaviours of individuals during their foraging trips, we used the Expectation Maximisation binary Clustering (EMbC) algorithm (Garriga et al. 2016), a variant of the maximum likelihood estimation of Gaussian mixture models (Redner \& Walker 1984). The EMbC algorithm is a robust, non-supervised multi-variate clustering algorithm that considers correlation and uncertainty of variables, giving a meaningful local labelling easily linked to biological interpretations. The annotation of behaviours was based on 2 input variables: the speed and the turning angle, obtained from successive locations. First, all tracks were linearly interpolated with 1 location every 2 min and the maximum speed was set to $90 \mathrm{~km} \mathrm{~h}^{-1}$ (Weimerskirch et al. 2005b). Each location was clustered by the algorithm into 4 behaviour categories (Table 2): High velocity/Low turn (HL), High velocity/High turn (HH), Low velocity/Low turn (LL), Low velocity/High turn (LH). A behavioural mode was assigned to each cluster, as suggested by Louzao et al. (2014). The HL and $\mathrm{HH}$ labels correspond respectively to travelling and relocating. Relocating reflects important turns with a steady speed and can be interpreted as a displacement

Table 1. Study sites and data collected on incubating red-footed boobies fitted with GPS loggers. EU: Europa, WA: Walpole, CH: Chesterfield, GEN: Genovesa, CI: Christmas. S: South, E: East. RFB: red-footed booby Sula sula, BB: brown booby S. leucogaster, MB: masked booby $S$. dactylatra, AB: Abbott's booby Papasula abbotti, NB: Nazca booby $S$. granti. Dates are given as mm/dd

\begin{tabular}{|c|c|c|c|c|c|c|c|c|}
\hline Site & $\begin{array}{l}\text { Island } \\
\text { size } \\
\left(\mathrm{km}^{2}\right)\end{array}$ & $\begin{array}{l}\text { Colony } \\
\text { location }\end{array}$ & $\begin{array}{c}\text { Main } \\
\text { wind } \\
\text { direction }\end{array}$ & Study period & $\begin{array}{l}\text { Number } \\
\text { of RFB } \\
\text { tracked }\end{array}$ & $\begin{array}{l}\text { Number } \\
\text { of tracks }\end{array}$ & $\begin{array}{c}\text { RFB } \\
\text { population } \\
\text { size (pairs) }\end{array}$ & $\begin{array}{c}\text { Other } \\
\text { booby species } \\
\text { (pairs) }\end{array}$ \\
\hline EU & 28 & $40.3^{\circ} \mathrm{E}, 22.3^{\circ} \mathrm{S}$ & $\mathrm{SE}$ & $\begin{array}{l}\text { 2003: 09/08-09/23 } \\
\text { 2013: 09/23-10/16 }\end{array}$ & $\begin{array}{c}9 \\
13\end{array}$ & $\begin{array}{c}9 \\
34\end{array}$ & $2800-3800^{\mathrm{a}}$ & None \\
\hline WA & 2 & $168.9^{\circ} \mathrm{E}, 22.6^{\circ} \mathrm{S}$ & SE & 2014: 09/20-09/24 & 7 & 13 & ca. $1000^{\mathrm{b}}$ & $\mathrm{BB}(100 \mathrm{~s})^{\mathrm{c}}$ \\
\hline $\mathrm{CH}$ & $<10$ & $158.4^{\circ} \mathrm{E}, 9^{\circ} 9^{\circ} \mathrm{S}$ & $\mathrm{SE}$ & 2012: 05/27-06/02 & 17 & 25 & $7200-7300^{\mathrm{d}}$ & $\begin{array}{l}\mathrm{MB}\left(280-500^{\mathrm{d}}\right) \\
\mathrm{BB}\left(3800-5800^{\mathrm{d}}\right)\end{array}$ \\
\hline GEN & 135 & $-89.9^{\circ} \mathrm{E}, 0.3^{\circ} \mathrm{S}$ & $\mathrm{S}$ & $\begin{array}{l}\text { 2009: } 11 / 13-11 / 25 \\
\text { 2014: } 11 / 10-11 / 25\end{array}$ & $\begin{array}{l}26 \\
36\end{array}$ & $\begin{array}{l}37 \\
42\end{array}$ & $140000^{\mathrm{e}}$ & $\mathrm{NB}\left(>1000^{\mathrm{b}}\right)$ \\
\hline $\mathrm{CI}$ & 14 & $105.6^{\circ} \mathrm{E}, 10.5^{\circ} \mathrm{S}$ & $\mathrm{SE}$ & 2014: 07/29-08/22 & 15 & 39 & $12000^{\mathrm{f}}$ & $\begin{array}{l}\text { BB }\left(5000^{f}\right) \\
\text { AB }\left(2500^{f}\right)\end{array}$ \\
\hline
\end{tabular}


Table 2. Values of the delimiters of speed and turning angle of the 4 behaviours assigned by the Expectation Maximisation binary Clustering (EMbC) algorithm

\begin{tabular}{|lcccc|}
\hline Behaviour & $\begin{array}{c}\text { Speed min } \\
\left(\mathrm{km} \mathrm{h}^{-1}\right)\end{array}$ & $\begin{array}{c}\text { Speed max } \\
\left(\mathrm{km} \mathrm{h}^{-1}\right)\end{array}$ & $\begin{array}{c}\text { Turn min } \\
\text { (radians) }\end{array}$ & $\begin{array}{c}\text { Turn max } \\
\text { (radians) }\end{array}$ \\
\hline Resting & 0 & 4 & 0 & 0.30 \\
Intense foraging & 0 & 14 & 0.30 & 3.14 \\
Travelling & 4 & 90 & 0 & 0.31 \\
Relocating & 14 & 90 & 0.31 & 3.14 \\
\hline
\end{tabular}

between restricted areas of intensive foraging. The LL label corresponds to birds resting at the sea surface, mostly sitting on the water and drifting in a single direction induced by surface currents (Weimerskirch et al. 2002). The LH label was interpreted as intensive foraging. A smoothing procedure included in the package was applied to better account for the temporal associations among behaviours. All trips from all breeding colonies were treated simultaneously in the analysis which was conducted with the $\mathrm{R}$ package $E M b C$ (Garriga et al. 2016). Proportions of each behaviour along tracks were compared between sites and during daytime or night-time, i.e. when the sun was $>6^{\circ}$ below the horizon. All analyses were conducted in R 3.1.2 (R Development Core Team 2014).

Area-restricted search (ARS) was defined as at least 3 successive locations (i.e. 4 min) labelled as intensive foraging by the EMbC algorithm. To simplify the description of the different behaviours along the trajectory, we merged ARS zones when $\leq 4$ locations labelled with other behaviours were observed between them (i.e. $10 \mathrm{~min}$ ). The number of ARS zones per hour and their duration were calculated. The area covered was estimated through the minimum convex polygon around all the locations of a specific ARS zone. Each ARS was summarised in 1 central location by taking the median latitude and longitude.

\section{Foraging behaviour and environmental drivers}

Kernel estimation (Worton 1989) was used to determine the utilisation distribution (UD) probability based on the locations of individuals. Kernel density estimates offer the advantage of being widely used to identify population-level core habitat areas. We used the function kernelUD implemented in the R package adehabitatHR (Calenge 2006) using the reference bandwidth which produces contiguous cores without over-smoothing. Choosing a secant projection and a narrow zone minimises the distortions in a map generated from projection. To estimate the size of general (95\%) and core $(50 \%)$ foraging areas, we used the function getverticeshr with adapted local projections (Europa: Moznet / UTM zone 37S; Genovesa: WGS 84 / UTM zone 16S; Christmas: RGNC9193 / Lambert New Caledonia; Chesterfield and Walpole: RGNC 1991 / Lambert New Caledonia). Depth was obtained from the 1 arc-minute resolution GEBCO bathymetric dataset using the $\mathrm{R}$ package marmap (Pante \& Simon-Bouhet 2013). Monthly composites of chlorophyll a concentration ( $\mathrm{chl} a_{\text {, in }}$ $\mathrm{mg} \mathrm{m}^{-3}$ ) were obtained at a spatial resolution of $4 \mathrm{~km}$ from the Aqua MODIS satellite using the R package rerddap (Chamberlain 2016). At a finer time-scale, we used a self-written script to obtain $11 \mathrm{~d}$ composites of chl a concentration at $4 \mathrm{~km}$ resolution (GlobColour, merged sensor type and GSM algorithm) using the software GNA Octave (Eaton et al. 2014).

For each site, the accessible area was defined by a circle around the colony with a radius corresponding to the maximum range recorded by GPS tracking. The foraging area was delimited by the minimum convex polygon that included all ARS zones of all birds. The accessible but not prospected area was defined as the accessible area to which the prospected area was subtracted. Monthly chl a concentration was compared between prospected areas and non-prospected areas. Comparisons between travelling and ARS locations were made using $11 \mathrm{~d}$ chl a concentration. Prior to data analysis, travelling locations were resampled with 1 location every 10 min to reduce autocorrelation and have a number of locations in the same order of magnitude than the number of ARS zones.

\section{Statistical analysis}

As some individuals were tracked during several trips, linear mixed-effects models with 'individual' as random factor were applied to avoid pseudoreplication. We used the function lmer from the $\mathrm{R}$ package Ime4 (Bates et al. 2015) to test for differences in trip parameters between breeding colonies. Tukey's HSD test was used to calculate post-hoc comparisons on each factor in the model using the function glht from the R package multcomp (Hothorn et al. 2008). When residuals were not normally distributed, variables were square-root transformed. When the data still did not meet the assumptions, we used a Kruskal-Wallis rank sum test and Tukey and Kramer (Nemenyi) test for pairwise comparisons with Tukey-Dist approximation for independent samples from the $\mathrm{R}$ package 

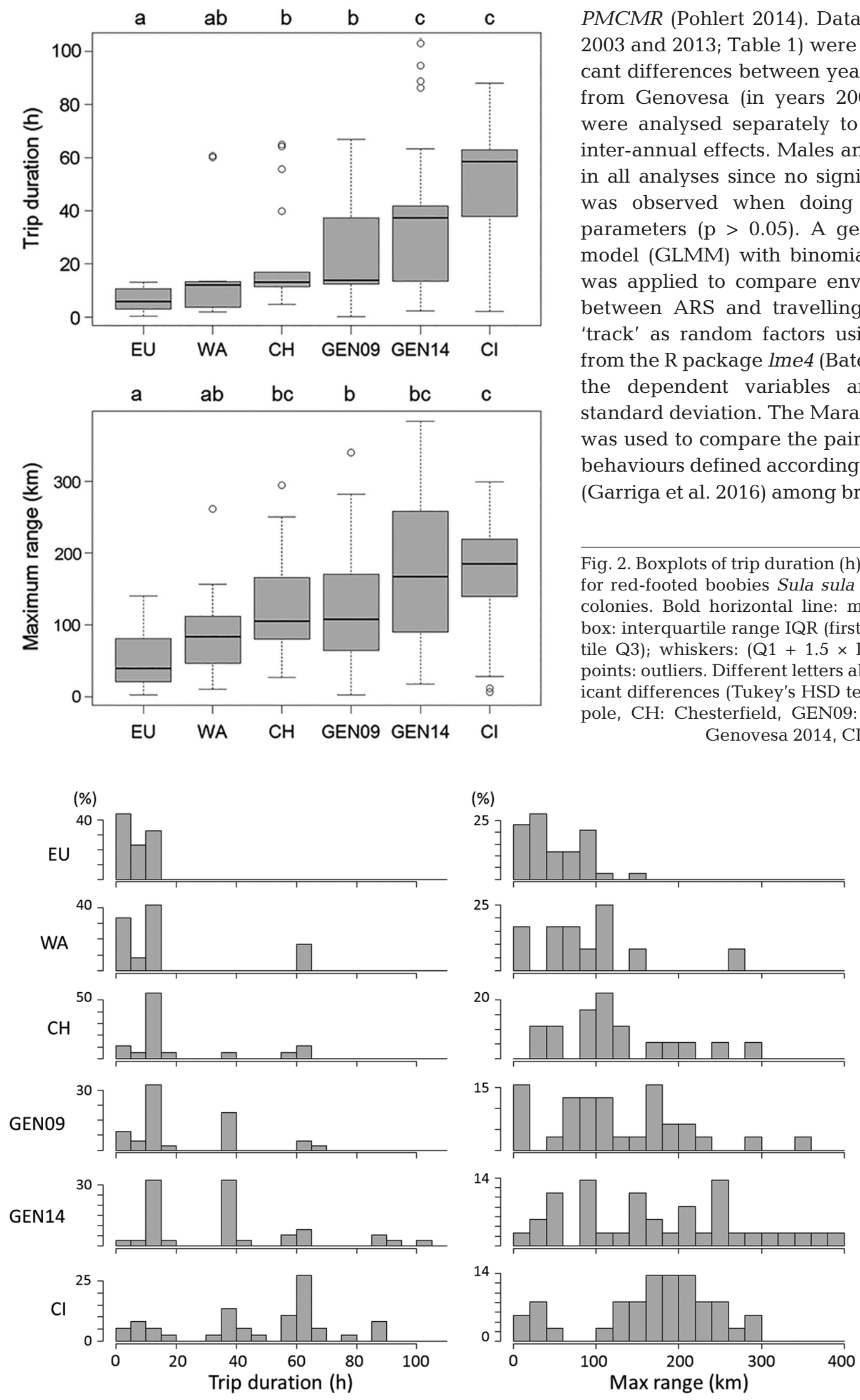

Fig. 3. Distribution of trip duration (h) and maximum range $(\mathrm{km})$ for red-footed boobies Sula sula from 5 different breeding colonies. EU: Europa, WA: Walpole, $\mathrm{CH}$ : Chesterfield, GEN09: Genovesa 2009, GEN14: Genovesa 2014, CI: Christmas
PMCMR (Pohlert 2014). Data from Europa (in years 2003 and 2013; Table 1) were pooled since no signififrom Genovesa (in years 2009 and 2014; Table 1) were analysed separately to take into account the inter-annual effects. Males and females were pooled in all analyses since no significant effect of the sex was observed when doing comparisons of track parameters $(p>0.05)$. A generalised linear mixed model (GLMM) with binomial family and logit link was applied to compare environmental parameters between ARS and travelling with 'individual' and 'track' as random factors using the function glmer from the R package lme4 (Bates et al. 2015). Values of the dependent variables are given as mean \pm standard deviation. The Marascuilo (1966) procedure was used to compare the pairwise proportions of the behaviours defined according to the EMbC algorithm (Garriga et al. 2016) among breeding colonies.

Fig. 2. Boxplots of trip duration $(\mathrm{h})$ and maximum range $(\mathrm{km})$ for red-footed boobies Sula sula from 5 different breeding colonies. Bold horizontal line: median of the distribution; terquartile range IQR (first quartile Q1 to third quarpoints: outliers. Different letters above boxes indicate signifpole, CH: Chesterfield, GEN09: Genovesa 2009, GEN14: Genovesa 2014, CI: Christmas icant differences (Tukey's HSD test). EU: Europa, WA: Wal- 


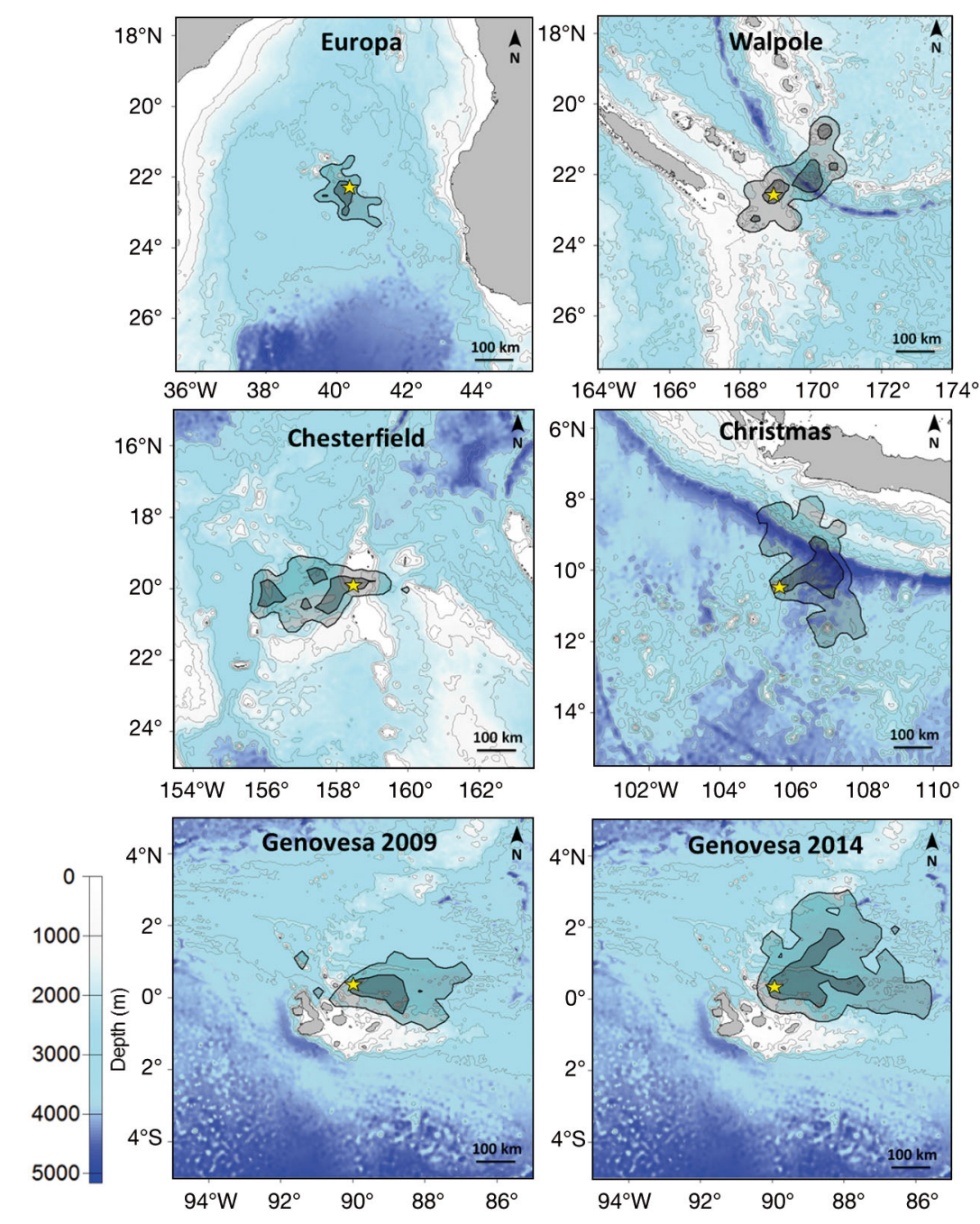

Fig. 4. General (95\% kernel density estimation, light shading) and core (50\% kernel density estimation, dark shading) foraging areas of red-footed boobies Sula sula from 5 different breeding colonies superimposed on bathymetric maps. Colony sites are indicated by a yellow star

\section{RESULTS}

\section{Trip parameters}

Foraging parameters varied extensively between sites. Individuals from Europa undertook short foraging trips exclusively, lasting on average less than $7 \mathrm{~h}$, with a maximum range of $50 \mathrm{~km}$, and never spent the night at sea (Figs. 2 \& 3). At Walpole, apart from 2 trips that lasted $60 \mathrm{~h}$ including 3 nights at sea, trips were only slightly longer than those of Europa (mean duration $8 \mathrm{~h}$, mean range $80 \mathrm{~km})$. At Chesterfield, some trips were longer than $24 \mathrm{~h}$ and nights spent at sea were frequently observed, yielding a mean trip duration of $21 \mathrm{~h}$ and a maximum range of $125 \mathrm{~km}$. In contrast, overnight trips were common at Genovesa, with a mean duration of $22 \mathrm{~h}$ and range of $122 \mathrm{~km}$ in 2009, and higher values in 2014 (37 h and $176 \mathrm{~km}$ ). Four trips included 4 nights at sea and 1 trip included 5 nights at sea. The furthest location recorded was $472 \mathrm{~km}$ away from the colony. Birds from Christmas Island made significantly longer trips in duration than those from the other sites $(45 \mathrm{~h}$ on average), but the maximum range recorded (164 km on average) was not greater. (Figs. 2 \& 3) Four trips included 4 nights at sea.

All the foraging areas of RFB were over oceanic waters but their size clearly differed between sites (Fig. 4). Europa had the smallest foraging area evenly distributed around the island (95\% and 50\% kernels: 22243 and $3863 \mathrm{~km}^{2}$, respectively; Fig. 4). The 4 other sites showed directionality in foraging area. Birds foraged principally to the north-east of Walpole (54988, $12420 \mathrm{~km}^{2}$ ), to the west of Chesterfield $\left(57992,14422 \mathrm{~km}^{2}\right)$, to the east of Genovesa (2009: $60438,12497 \mathrm{~km}^{2}$; 2014: $132784,28206 \mathrm{~km}^{2}$ ) and to the east of Christmas (111900, 18388 $\mathrm{km}^{2}$ ). The surface area covered by birds from Genovesa in 2014 was approximately 6 times larger when compared to birds from Europa. The direction of all foraging areas was not related to the main wind direction (Table 1, Fig. 4).

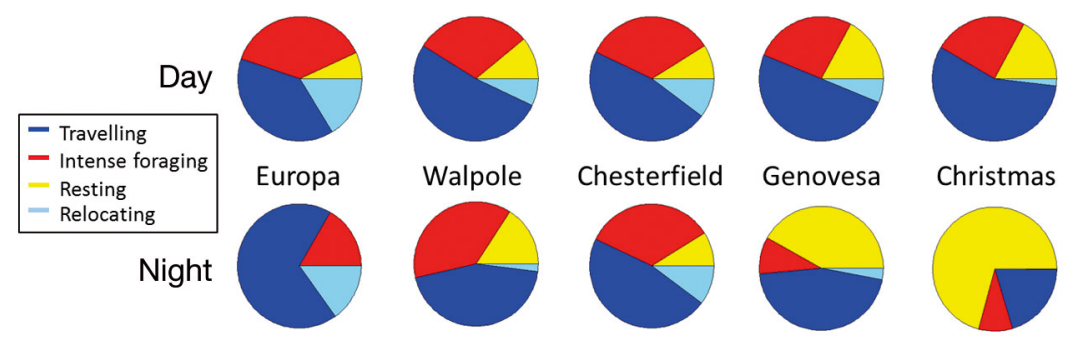

Fig. 5. Mean proportion of each behaviour for red-footed boobies Sula sula from 5 different breeding colonies. Behaviour was determined along tracks according to Expectation Maximisation binary Clustering (EMbC) analysis. Results are displayed in the form of pie charts according to the site and the period (day or night) 
The multiple pairwise comparisons (Marascuilo procedure) showed that the percentages of the different behaviours during the foraging trips were not significantly different among sites during the day (Fig. 5). During the night, the high proportion of resting behaviour at Christmas was significantly different from all the other sites. The proportion of resting behaviour at Genovesa differed also from Europa and Chesterfield. The proportion of relocating behaviour at Christmas was significantly different from Europa and Chesterfield. After sunset, individuals from Europa were mainly travelling for short periods until they reached the colony. Foraging bouts occurred occasionally and birds never rested on the sea surface. At the other sites, the more the birds tended to spend entire nights at sea, the more a resting behaviour was observed.

Only $2.5 \%$ of the dataset ( 5 tracks from 4 birds) did not contain ARS. The number of ARS zones per hour differed slightly between breeding colonies $\left(F_{4,91}=\right.$ $2.81, \mathrm{p}=0.03$ ), with 0.5 to $0.7 \mathrm{ARS}^{-1}$ on average (Fig. 6). Only Europa and Christmas differed significantly (Tukey's HSD test, $\mathrm{p}=0.016$ ), with the highest values observed at Europa (up to $1.67 \mathrm{ARS} \mathrm{h}^{-1}$ ). The mean duration of ARS differed between sites $\left(F_{4,91}=\right.$ 5.91, p < 0.001). ARS lasted on average between 16 and 28 min (Fig. 6). ARS of birds from Europa and Chesterfield, making relatively short trips, were significantly longer than those of birds from Genovesa (Tukey's HSD test, $\mathrm{p}=0.01$ and $\mathrm{p}=0.04$, respectively) and Christmas (Tukey's HSD test, $\mathrm{p}=0.01$ and $\mathrm{p}=$ 0.03 , respectively). Walpole was intermediate (Tukey's HSD test, $p>0.05$ ). Long ARS lasting more than $1 \mathrm{~h}$ were occasionally observed at Europa but were rare at other sites. Mean ARS surface area ranged between 0.45 and $1.86 \mathrm{~km}^{2}$ (Fig. 6), with often larger values for Europa and Chesterfield, which were statistically different from Christmas (Tukey's HSD test, $p=0.01$ and $p=0.04$, respectively). No inter-annual effect was observed at Genovesa for the 3 descriptive parameters (Tukey's HSD test, $\mathrm{p}>0.05$ ).

\section{Foraging areas and oceanographic conditions}

For Europa, Genovesa and Walpole, the incubation period occurred 2 to 3 mo after the annual peak of chl $a$ in the waters around each island, and 2 to 3 mo before the peak at Chesterfield and Christmas (Fig. 7). We observed a high variability in the concentration of chl a among study sites. Inside the foraging areas (Fig. 8), waters around Europa and Walpole showed a particularly low concentration (mean
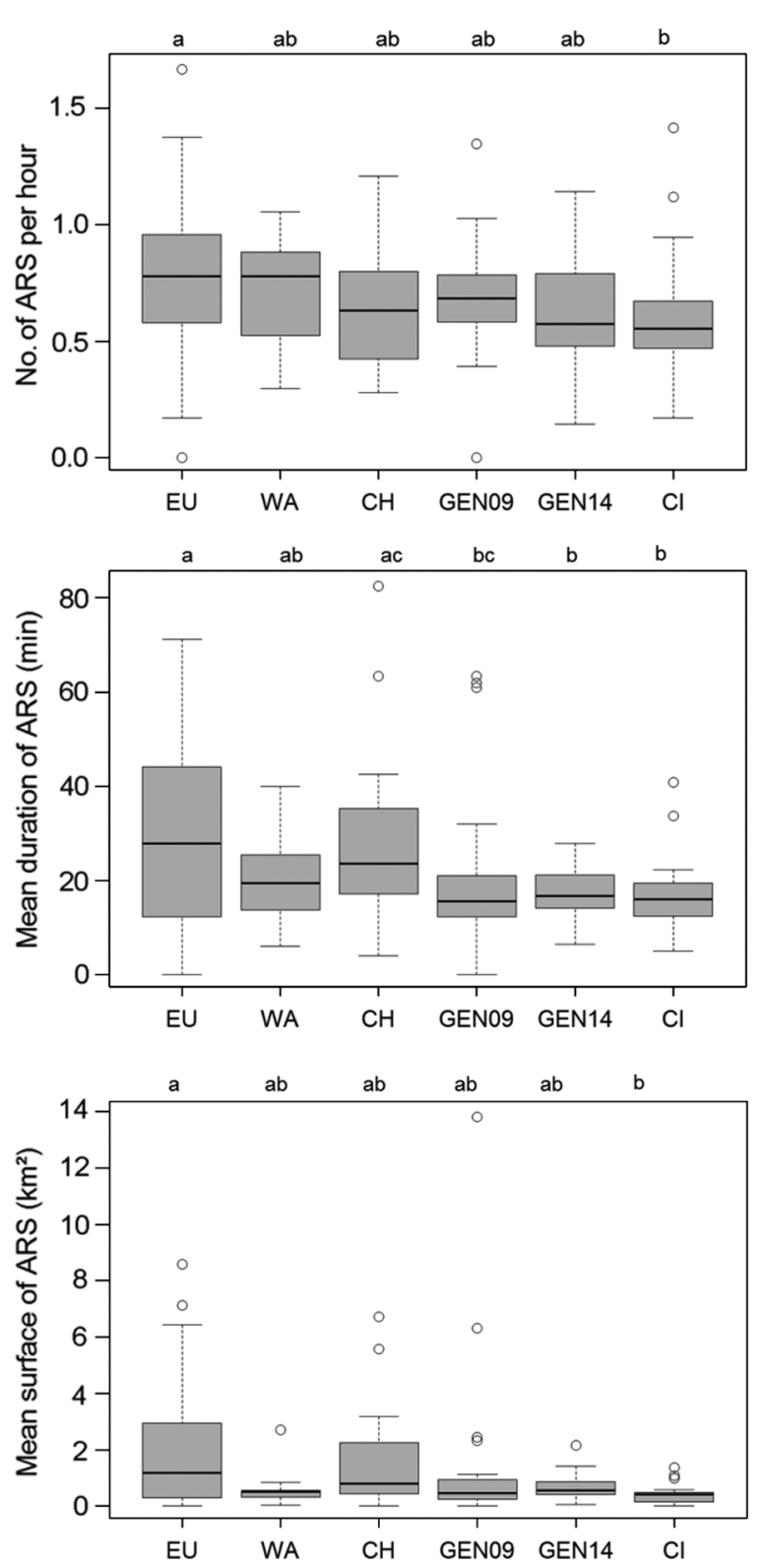

Fig. 6. Number per hour, mean duration (min) and mean surface area $\left(\mathrm{km}^{2}\right)$ of area-restricted search (ARS) zones for red-footed boobies Sula sula from 5 different breeding colonies. Boxplot details as in Fig. 2. Different letters above boxes indicate significant differences (Tukey's HSD test). EU: Europa, WA: Walpole, CH: Chesterfield, GEN09: Genovesa 2009, GEN14: Genovesa 2014, CI: Christmas

$0.07 \mathrm{mg} \mathrm{m}^{-3}$ ), which was significantly different from the 3 other sites (Tukey's HSD test, $\mathrm{p}<0.05$ ). The chl a concentration was considerably higher in the foraging areas of birds from Genovesa and Christmas (more than $0.15 \mathrm{mg} \mathrm{m}^{-3}$ on average). Chesterfield was intermediate $\left(0.11 \mathrm{mg} \mathrm{m}^{-3}\right.$ on average) but not significantly different from Genovesa and Christmas (Tukey's HSD test, $\mathrm{p}>0.05$ ). 

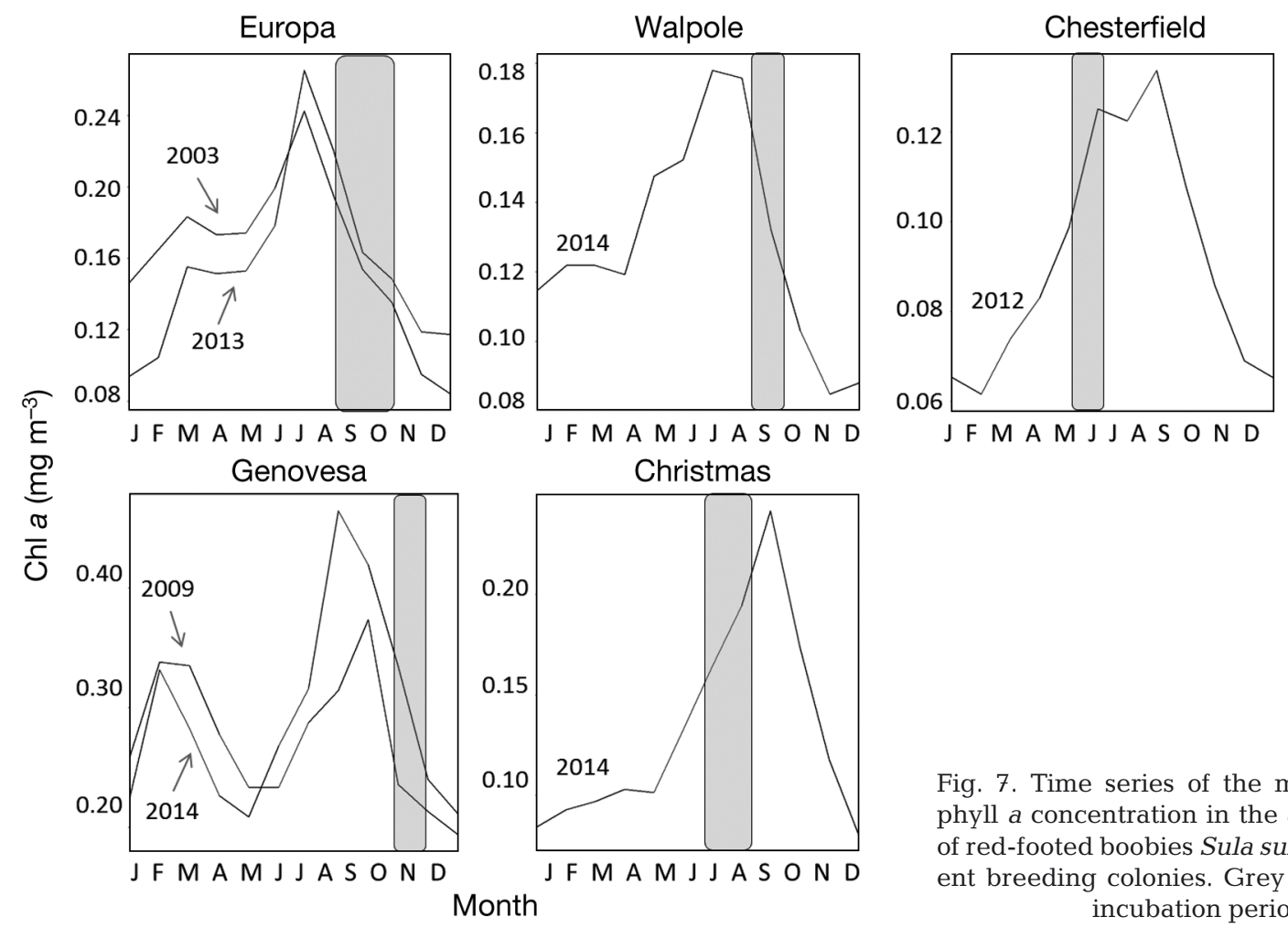

Fig. 7. Time series of the monthly chlorophyll a concentration in the accessible area of red-footed boobies Sula sula from 5 different breeding colonies. Grey boxes indicate incubation periods

Birds from Europa foraged in all directions with no specific orientation (Fig. 8). The foraging areas of the 4 other sites were clearly oriented towards specific directions. RFB did not seem to especially favour areas of higher chl a concentration (Table 3). A slightly higher monthly chl a concentration in the prospected area was observed in Europa and was more pronounced in Christmas. In the 3 other sites, the mean chl a concentration was similar or slightly significantly higher in the non-prospected area. Regarding the bathymetry, birds foraged over relatively shallow oceanic waters at Europa, Chesterfield, Genovesa and Walpole, with average depths ranging between 2000 and $3000 \mathrm{~m}$ (Table 3). Most birds from Christmas moved over a deep oceanic trench during their foraging trips (Fig. 4), leading to an average depth of approximately $5000 \mathrm{~m}$ in the foraging area. Depending on the site, the bathymetry was alternatively higher in the prospected or the non-prospected area (Table 3).

At a finer scale, the $11 \mathrm{~d}$ composite chl a concentration and the bathymetry were compared between ARS and travelling segments of a trip (Table 4). We found no significant differences in chl a for Europa (GLMM, p = 0.50) and Genovesa (GLMM, p = 0.08 and $\mathrm{p}=0.62$ in 2009 and 2014, respectively). Higher values were observed inside ARS than during travelling for Christmas (GLMM, $\mathrm{p}<0.001)$ and lower values for Chesterfield (GLMM, $\mathrm{p}=0.03$ ) and Walpole
(GLMM, $p=0.05)$. No significant differences in bathymetry between ARS and travelling were observed in Europa, Walpole and Chesterfield. ARS occurred in significantly deeper waters than travelling in Genovesa (GLMM, $\mathrm{p}=0.01$ and $\mathrm{p}<0.0001$ in 2009 and 2014, respectively) and Christmas (GLMM, p < 0.0001).

\section{DISCUSSION}

This study is the first to compare the foraging behaviour and its relationship with oceanographic conditions for a seabird species during the same breeding stage across breeding colonies over a large extent of the species' pantropical range. We found significant inter-colony differences in foraging behaviour, especially extensive differences in foraging duration and range between sites. These differences were not directly explained by chl a concentration, a proxy of marine productivity. However, some similarities common to all sites were observed at a fine spatio-temporal scale, such as the proportion of the different behaviours during the day and the main characteristics of ARS zones. Beyond environmental conditions, we suggest that intra- and interspecific competition within a colony and with adjacent colonies can explain the large diversity of foraging strategies used by the red-footed booby. 


\section{Intraspecific differences in foraging behaviour}

Our study confirms that RFBs are oceanic foragers throughout their range but also indicates that the foraging behaviour differs substantially among colonies. Birds nesting on Europa undertook relatively short and exclusively diurnal foraging trips. The foraging trips of the birds from Walpole were similar to those from Europa, except for 2 trips including nights at sea. The duration of trips was respectively higher at Chesterfield, Genovesa and Christmas, where trips lasting more than a day were frequently observed. The longest durations and ranges were observed at Genovesa, but birds from Christmas made the longest trips on average. Until the present study, redfooted boobies were thought to undertake diurnal foraging trips exclusively, based on preliminary results from GPS tracking (Weimerskirch et al. 2005a, Young et al. 2010). The only locality where it was suggested from observation that trips can last more than $1 \mathrm{~d}$ was in the Galapagos (Nelson 1978, Schreiber et al. 1996). Here we confirmed the previous visual observations in the Galapagos, reporting birds leaving the colony of Genovesa for up to $5 \mathrm{~d}$, and we showed that during these long trips birds can forage at up to $472 \mathrm{~km}$ from the colony. At night, the percentages of the different behaviours varied extensively across the 5 breeding colonies of RFB. At Europa, birds travelled rapidly in order to return to the colony and rest on land. For the other breeding colonies, slow and linear trajectories suggested that the birds floated on the water during the night, being drifted by surface currents. Foraging activity was rare, occurring presumably during dawn and dusk. Since RFBs are visual foragers with likely crepuscular vision, nocturnal foraging is constrained by the lack of ambient light (Ashmole \& Ashmole 1967). Weimerskirch et al. (2005a) suggested that predation may be a reason for the RFBs from Europa to stay on land during the night. RFBs from Genovesa, Chesterfield, Walpole and Christmas frequently drifted on the sea surface at night,
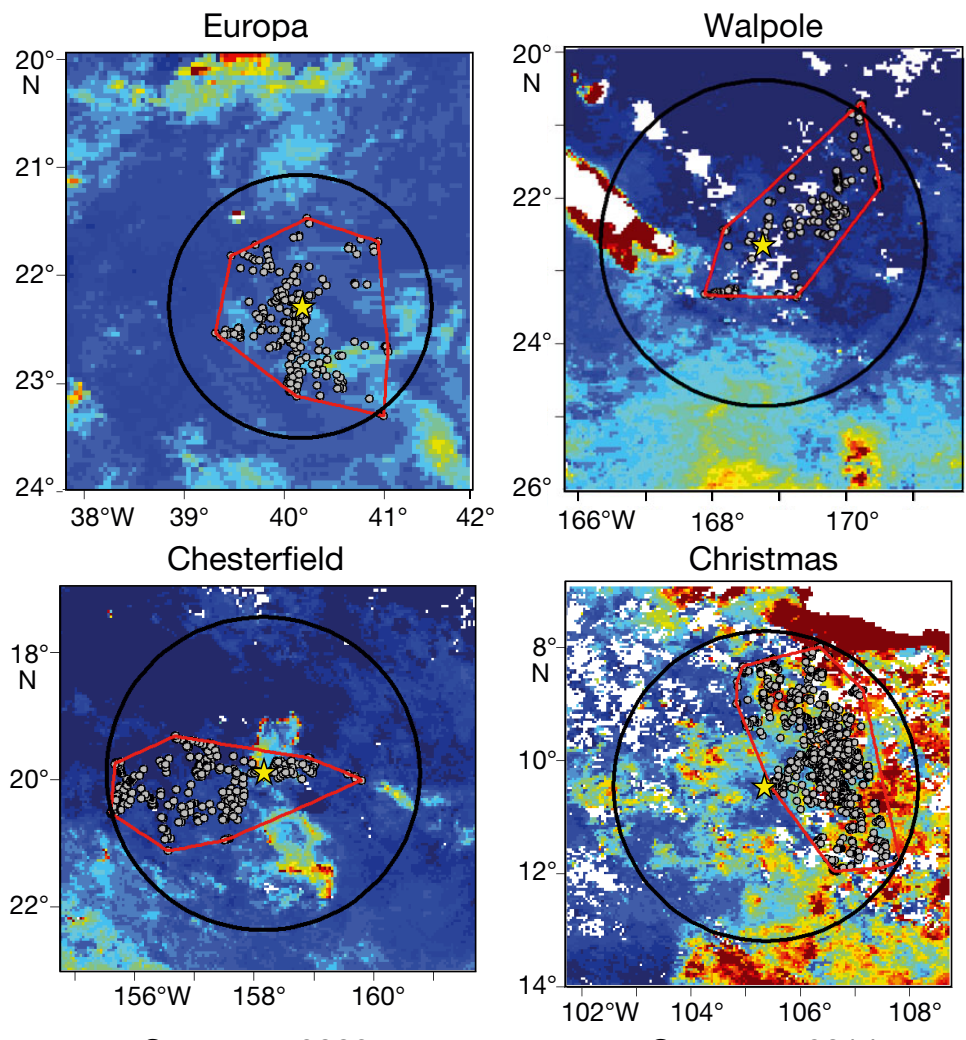

Genovesa 2009
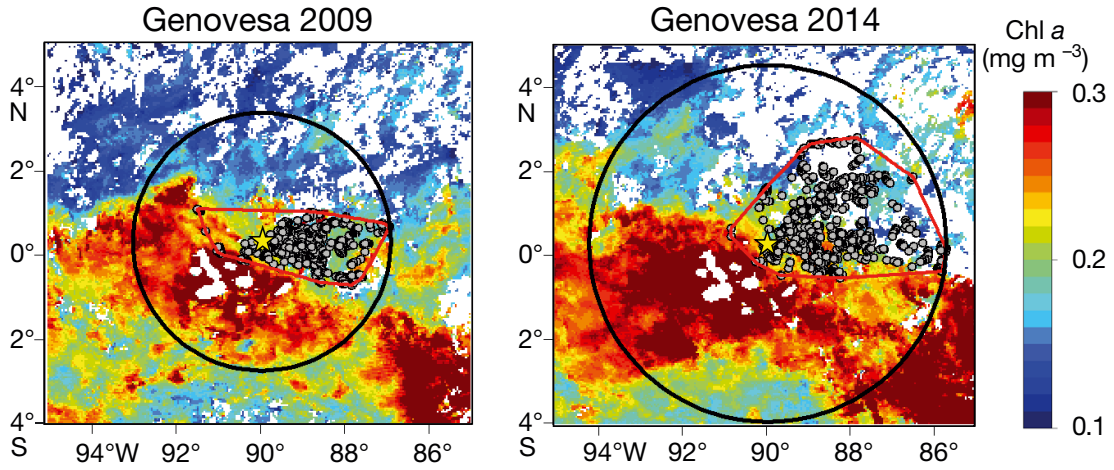

Fig. 8. Foraging areas (red polygons) and accessible areas (black circles) of red-footed boobies Sula sula from 5 different breeding colonies, superimsites; grey dots: centroid of each area-restricted search (ARS) zone

susceptible to attacks from below. Observations of foot damage to Nazca boobies Sula granti in the Galapagos indicated possible attacks from toothed sub-surface predators (Zavalaga et al. 2012). Sharks are known to attack seabirds (Johnson et al. 2006, Meyer et al. 2010), but since they are potentially present at all 5 studied sites, predation risk may not be the main factor explaining the different foraging behaviour observed. Sharks may rely on vision to detect seabirds on the surface, implying that resting at night may not be a high-risk behaviour. Birds could then afford nocturnal predation risk, for 
Table 3. Comparison of the chlorophyll a concentration (chl $a_{\text {, }}$ in $\mathrm{mg} \mathrm{m}^{-3}$ ) and the bathymetry (bathy, in $\mathrm{m}$ ) between the foraging area and the accessible but non-prospected area of red-footed boobies Sula sula from 5 different breeding colonies. Values expressed as mean \pm SD and significantly higher means are in bold for pairwise comparisons. EU: Europa, WA: Walpole, CH: Chesterfield, GEN09: Genovesa 2009, GEN14: Genovesa 2014, CI: Christmas

\begin{tabular}{|lccc|}
\hline \multirow{2}{*}{$\begin{array}{l}\text { Breeding } \\
\text { colony }\end{array}$} & \multirow{2}{*}{ Para- } & \multicolumn{2}{c|}{ Area category } \\
\cline { 3 - 4 } meter & Non-prospected & Foraging \\
\hline EU & chl $a$ & $0.149 \pm 0.014$ & $\mathbf{0 . 1 5 3} \pm \mathbf{0 . 0 1 8}$ \\
& bathy & $\mathbf{2 9 7 5} \pm \mathbf{5 5 4}$ & $3023 \pm 391$ \\
WA & chl $a$ & $\mathbf{0 . 1 2 9} \pm \mathbf{0 . 0 3 3}$ & $0.111 \pm 0.017$ \\
& bathy & $\mathbf{2 2 9 0} \pm \mathbf{1 4 8 1}$ & $2634 \pm 1383$ \\
CH & chl $a$ & $0.111 \pm 0.033$ & $0.111 \pm 0.027$ \\
& bathy & $2176 \pm 1092$ & $\mathbf{2 0 5 8} \pm \mathbf{7 9 7}$ \\
GEN09 & chl $a$ & $\mathbf{0 . 2 0 7} \pm \mathbf{0 . 0 5 0}$ & $0.190 \pm 0.036$ \\
& bathy & $2726 \pm 709$ & $\mathbf{2 2 6 8} \pm \mathbf{5 0 3}$ \\
GEN14 & chl $a$ & $\mathbf{0 . 2 2 0} \pm \mathbf{0 . 0 4 9}$ & $0.203 \pm 0.039$ \\
& bathy & $2763 \pm 679$ & $\mathbf{2 2 0 3} \pm \mathbf{5 1 2}$ \\
CI & chl & $0.182 \pm 0.039$ & $\mathbf{0 . 2 0 7} \pm \mathbf{0 . 0 4 3}$ \\
& bathy & $\mathbf{4 9 0 5} \pm \mathbf{1 0 5 5}$ & $5096 \pm 1283$ \\
& & & \\
\hline
\end{tabular}

Table 4. Comparison of chlorophyll a concentration ( $\mathrm{chl} a$, in $\mathrm{mg} \mathrm{m}^{-3}$ ) and bathymetry (bathy, in $\mathrm{m}$ ) between travelling and area-restricted search (ARS) zones of red-footed boobies Sula sula from 5 different breeding colonies (see Table 3 for abbreviations). Significantly higher values (mean \pm $\mathrm{SD}$ ) generated from generalised linear mixed models (GLMM) are in bold

\begin{tabular}{|c|c|c|c|c|c|}
\hline \multirow{2}{*}{$\begin{array}{l}\text { Breeding } \\
\text { colony }\end{array}$} & \multirow{2}{*}{$\begin{array}{l}\text { Para- } \\
\text { meter }\end{array}$} & \multicolumn{2}{|c|}{$\longrightarrow$ Behaviour $\longrightarrow$} & \multicolumn{2}{|c|}{ Test } \\
\hline & & Travelling & ARS & $z$-value & p-value \\
\hline \multirow[t]{2}{*}{ EU } & $\operatorname{chl} a$ & $0.076 \pm 0.059$ & $0.069 \pm 0.053$ & -0.669 & 0.5036 \\
\hline & bathy & $2828 \pm 703$ & $2890 \pm 631$ & -1.045 & 0.2961 \\
\hline \multirow[t]{2}{*}{ WA } & $\operatorname{chl} a$ & $0.077 \pm 0.015$ & $0.069 \pm 0.017$ & -1.961 & 0.0499 \\
\hline & bathy & $2369 \pm 1636$ & $3153 \pm 1806$ & -0.869 & 0.3851 \\
\hline \multirow[t]{2}{*}{$\mathrm{CH}$} & $\operatorname{chl} a$ & $0.119 \pm 0.028$ & $0.112 \pm 0.022$ & -2.179 & 0.0294 \\
\hline & bathy & $1894 \pm 864$ & $1969 \pm 853$ & -1.588 & 0.1122 \\
\hline \multirow[t]{2}{*}{ GEN09 } & $\operatorname{chl} a$ & $0.111 \pm 0.055$ & $0.103 \pm 0.038$ & -1.747 & 0.0806 \\
\hline & bathy & $1924 \pm 507$ & $2029 \pm 496$ & -3.195 & 0.014 \\
\hline \multirow[t]{2}{*}{ GEN14 } & $\operatorname{chl} a$ & $0.190 \pm 0.067$ & $0.184 \pm 0.061$ & -0.500 & 0.617 \\
\hline & bathy & $2154 \pm 508$ & $2288 \pm 463$ & -4.239 & $<0.001$ \\
\hline \multirow[t]{2}{*}{$\mathrm{CI}$} & $\operatorname{chl} a$ & $0.146 \pm 0.063$ & $0.156 \pm 0.069$ & 3.708 & $<0.001$ \\
\hline & bathy & $5297 \pm 1221$ & $5503 \pm 1104$ & -3.423 & $<0.001$ \\
\hline
\end{tabular}

the social-natural environment (Haraway \& Maples 1998). Many similarities appeared in the way RFBs used their environment during the day. Generally, they left from and returned to the colony in a straight trajectory. During the middle sections of the foraging trip, birds simultaneously reduced their speed and increased their sinuosity, suggesting that they found a patch of prey (Weimerskirch et al. 2005a). ARS frequency, size and duration showed large variability within sites. This variability may reflect a fine adjustment of the time spent in a patch of food according to its prey abundance and distribution, before moving to another. In order to optimise their foraging trips, birds should minimise the travelling time between foraging areas and their colonies (Charnov 1976). ARS were more variable at Europa, where trips were short and strictly diurnal, with higher occurrence, larger sizes and longer durations than at the other breeding colonies. Furthermore, the EMbC behaviour analysis of birds from Europa showed a higher proportion of intensive foraging behaviour during trips, reflecting an optimisation of the daily trip. Overall similarity in foraging strategy might be related to the fact that tropical seabirds generally feed in association with subsurface predators like tuna and dolphins that make prey available at the surface (Au \& Pitman 1986). However, a study reported that RFBs from Hawaii did not associate with any subsurface predator in greater proportion than what would be expected by chance (Hebshi et al. 2008). Further research is still needed to better understand the foraging strategies of tropical seabirds in oligotrophic waters.

\section{Foraging behaviour and productivity}

Previous studies assumed that RFBs may forage in more productive areas (Ballance et al. 1997, Jaquemet et al. 2005, Weimerskirch et al. 2005a). How-

example, in cases of low prey encounter during the previous day (Zavalaga et al. 2012).

\section{Similarities in diurnal foraging}

Individuals of a species possess similar behaviours, even if discrete populations do not mix. This 'speciestypical behaviour' is influenced by species genes and ever, Young et al. (2010) did not find any major variation in chl a concentration around a site that harbours a large RFB colony, the Palmyra Atoll (Northern Pacific), that would support this hypothesis. After examining the chl a concentration inside prospected and non-prospected areas, we found that birds from Christmas Island targeted productive areas with deep sea bed, but birds from the other colonies did not. At all the remaining sites, birds 
would have been able to reach more productive waters within their range if they had flown in another direction. Top marine predators such as cetaceans and seabirds target productive waters to increase their encounter rate with prey patches in restricted areas (Jaquemet et al. 2005). At Europa, the feeding of great frigatebirds Fregata minor is positively linked with dynamical fronts at the edge of eddies (Weimerskirch et al. 2004, Tew Kai et al. 2009, De Monte et al. 2012, Jaquemet et al. 2014). However, the distribution of frigatebirds is negatively influenced by chl a concentration, suggesting that they do not directly target high primary productivity (Thiers et al. 2014). Similarly, the productivity found in the foraging area of masked boobies $S$. dactylatra in the eastern tropical Pacific is not significantly different from the non-prospected area within the foraging range of the population (Weimerskirch et al. 2008). As tropical waters are characterised by an overall lower productivity compared to temperate or polar waters (Longhurst \& Pauly 1987), the distribution and abundance of prey is believed to be more unpredictable than in colder waters (Ashmole 1971). Here we see that the chl a concentration is not a good indicator of foraging areas of RFB in tropical environments.

Time lags, physical forcings and food web processes can thwart the link between primary productivity and the distribution of predators. As seabirds do not feed directly on primary producers, a natural delay due to energy transfer between phytoplankton, fish or squid occurs. For example, in the Benguela Current system, this phenomenon takes up to several weeks (Grémillet et al. 2008). Moreover, seabird prey seems to be less uniformly distributed than plankton (Piontkovski \& Williams 1995). For top marine predators, long time-series of chl a may be better indicators of productive habitats than finer temporal-scale measurements (Suryan et al. 2012). Static non-biological features, such as water depth and distance to shore, can be better explanatory variables than chl a (Nur et al. 2011). Since we did not find a direct effect of the bathymetry or the chl $a$ in 4 of the 5 sites, other factors may account for the differences in foraging ranges observed between breeding colonies.

\section{Resource partitioning}

Resource competition may lead to adaptations that reduce niche overlap (Gause 1934) and thus explain differences in seabird foraging area and behaviour (Rome \& Ellis 2004, Lance et al. 2005). In mixed co- lonies, seabirds may have to cope with interspecific and intraspecific competition. Birds from larger colonies could also have to forage further than birds from smaller colonies because individuals foraging close to the colony may cause local prey depletion (Ashmole 1963, Furness \& Birkhead 1984, Jovani et al. 2016). The sizes of the RFB colonies differ extensively between the study sites. The small population at Europa (2800 to 3800 pairs, Le Corre \& Jouventin 1997) had the shortest foraging range while the large population at Genovesa (140 000 pairs, Nelson 1978) had the longest foraging range, suggesting that intraspecific competition may partly explain the differences in foraging range between breeding colonies. At Genovesa, high intraspecific competition may lead birds to travel for several days, including nights at sea, and thus reach great distances. Grémillet et al. (2004) studied 2 close colonies of Cape gannets Morus capensis in South Africa and found that birds from the larger colony did make foraging trips that were longer in duration and range. Similarly, mean foraging trip duration of the northern gannet M. bassanus from colonies in Britain and Ireland has been found to be positively correlated with colony size (Lewis et al. 2001). In tropical ecosystems, tracking of masked boobies from 2 islands differing in colony size, surrounded by similar oligotrophic waters, was also consistent with Ashmole's hypothesis (Oppel et al. 2015). At Clipperton (Pacific Ocean), masked boobies showed a particularly long foraging range (average range of $103 \mathrm{~km}$, maximum $242 \mathrm{~km}$; Weimerskirch et al. 2008) and the huge colony size (>100 000 individuals) might explain that range.

Present or even previous competition could produce interspecific variation in foraging behaviour (Trivelpiece et al. 1987). The RFB is the only booby species present at Europa, while the 4 other sites host 1 or 2 other booby species. Little or no interspecific competition could explain why foraging trips were almost evenly distributed in a short range around Europa, and only during the day. The RFB is the smallest booby species and may fly further in the presence of other booby species because of lower flight costs. RFBs incubating at Johnston Atoll (central Pacific) made diurnal trips significantly longer than those made by brown boobies $S$. leucogaster, with a mean duration of 14 and $6.7 \mathrm{~h}$, respectively (Lewis et al. 2004). RFBs and masked boobies from Palmyra Atoll showed strong differences in their foraging behaviour and ranges, with RFBs being again more pelagic than masked boobies (Young et al. 2010). The 2 same species at Tromelin Island (Indian Ocean), surrounded by more oligotrophic waters, 
demonstrated interspecific segregation at the level of core foraging areas but not at the scale of the whole foraging region (Kappes et al. 2011). However, intraand interspecific competition did not explain the higher maximum ranges observed at Tern Island (3000 to 5000 RFB pairs) compared to Palmyra Atoll that hosts 25000 RFB pairs and 1 more tropical booby species (Young et al. 2015). However, the 2 islands have different oceanographic contexts thus potential environmental effects may overshadow the competition effect.

Exclusion by adjacent colonies is also known to potentially influence the directionality of the foraging trips (Wakefield et al. 2013). The small foraging range observed in Europa may be caused by a low level of competition since the island hosts a relatively small RFB colony, with no other tropical boobies and no other island in the vicinity. Genovesa is one of the north-eastern islands of the Galapagos archipelago. Since the foraging range was clearly oriented towards the east, birds may avoid competition with colonies of other species that have shorter ranges (Anderson 1991). Lastly, no island is present in the vicinity of Christmas Island, where the foraging area towards Java Island seems to be mainly driven by the environment. Although resource partitioning between distant colonies is difficult to evaluate, our data suggest that resource partitioning may also have an influence on the foraging behaviour observed at the colony scale.

To conclude, the environmental context and competition may affect the foraging behaviour of the $\mathrm{RFB}$, a central-place forager in tropical oligotrophic waters. To better understand the patterns observed in infra-specific studies, multi-species studies and information about the local environment seem essential to assess the impact of each effect resulting in the foraging behaviour.

Acknowledgements. This research was supported by France's 'Iles Eparses' program (2011-2013) managed by the CNRS-Institut Ecologie et Environnement (InEE) with the financial support of the CNRS-InEE, CNRS-Institut National des Sciences de l'Univers (INSU), Institut de recherche pour le développement (IRD), Agence des aires marines protégées (AAMP) and the logistic support of Terres Australes et Antarctiques Françaises (TAAF). Research in the Chesterfield Islands took place during the MOMAlis cruise on board the RV 'Alis', funded in part by the Commission nationale de la flotte côtière, IRD and AAMP. This work was also part of the program EARLYLIFE, funded by a European Research Council Advanced Grant under the European Community's Seven Framework Program FP7/2007-2013 (Grant Agreement ERC-2012-ADG_20120314 to H.W.). We thank J. B. Pons, S. Jaquemet, M. Le Corre and M. Bastien for their assistance in the field. We thank the Galapagos National
Park Service and the Ministry of the Environment of Ecuador for permission to work in the park, and the Charles Darwin Research Station for logistical support. The work on Christmas Island (Indian Ocean) was conducted within the framework of the Christmas Island Seabird Project (www. seabirdproject.cx), which was supported by grants from the Universität Hamburg, Mini Wunderland Hamburg, CI Island Trust, CI Territory Week Committee, CI Tourist Association, and many private sponsors. Globetrotter Hamburg, Grube KG Hützel, Rische \& Herfurth Hamburg and The North Face USA provided in-kind support. Parks Australia North Christmas Island provided accommodation and logistical support. M. Gant, M. Misso, M. Orchard, M. Smith and their teams at CI National Park, as well as Prof. J. Ganzhorn and his laboratory at the University of Hamburg, Germany, provided invaluable help and support. M. Berlincourt and B. Holtmann helped in the field. During the fieldwork, J.C.H. was funded by a Marie Curie Research Fellowship from the European Union (PIEF-GA-2009-236295). Lastly, we thank the 3 anonymous reviewers whose suggestions helped improving the manuscript.

\section{LITERATURE CITED}

Anderson DJ (1991) Apparent predator limited distribution of Galápagos Red footed Boobies Sula sula. Ibis 133: 26-29

Ashmole NP (1963) The regulation of numbers of tropical oceanic birds. Ibis 103:458-473

Ashmole NP (1971) Seabird ecology and the marine environment. In: Farner DS, King JR (eds) Avian biology, Vol 1. Academic Press, New York, NY, p 223-287

Ashmole NP, Ashmole MJ (1967) Comparative feeding eco$\operatorname{logy}$ of sea birds of a tropical oceanic island. Bull Peabody Mus Nat Hist 24

Au DWK, Pitman RL (1986) Seabird interactions with dolphins and tuna in the eastern tropical Pacific. Condor 88: 304-317

* Ballance LT, Pitman RL, Reilly SB (1997) Seabird community structure along a productivity gradient: importance of competition and energetic constraint. Ecology 78: 1502-1518

* Bates D, Mächler M, Bolker B, Walker S (2015) Fitting linear mixed-effects models using lme4. J Stat Softw 67:1-48

* Birt VL, Birt TP, Goulet D, Cairns DK, Montevecchi WA (1987) Ashmole's halo: direct evidence for prey depletion by a seabird. Mar Ecol Prog Ser 40:205-208

* Borsa P, Pandolfi M, Andréfouët S, Bretagnolle V (2010) Breeding avifauna of the Chesterfield Islands, Coral Sea: current population sizes, trends, and threats. Pac Sci 64 : 297-314

*Burke CM, Montevecchi WA (2009) The foraging decisions of a central place foraging seabird in response to fluctuations in local prey conditions. J Zool (Lond) 278:354-361

* Calenge C (2006) The package 'adehabitat' for the R software: a tool for the analysis of space and habitat use by animals. Ecol Modell 197:516-519

Chamberlain S (2016) rerddap: General purpose client for 'ERDDAP' servers. R package version 0.3.4. https:// github.com/ropensci/rerddap

Charnov EL (1976) Optimal foraging, the marginal value theorem. Theor Popul Biol 9:129-136

*De Monte S, Cotté C, d'Ovidio F, Lévy M, Le Corre M, Weimerskirch H (2012) Frigatebird behaviour at the 
ocean-atmosphere interface: integrating animal behaviour with multi-satellite data. J R Soc Interface 9:3351-3358

Eaton JW, Bateman D, Hauberg S, Wehbring R (2014) GNU Octave version 3.8.1 manual: a high-level interactive language for numerical computations. CreateSpace Independent Publishing Platform, www.gnu.org/software/ octave/doc/interpreter/

Freeman R, Dennis T, Landers T, Thompson D, Bell E, Walker M, Guilford T (2010) Black petrels (Procellaria parkinsoni) patrol the ocean shelf-break: GPS tracking of a vulnerable procellariiform seabird. PLOS ONE 5:e9236

Furness RW, Birkhead TR (1984) Seabird colony distributions suggest competition for food supplies during the breeding season. Nature 311:655-656

* Garriga J, Palmer JR, Oltra A, Bartumeus F (2016) Expectation-maximization binary clustering for behavioural annotation. PLOS ONE 11:e0151984

Gause GF (1934) The struggle for existence. Williams and Wilkins, Baltimore, MD

Greenberg G, Haraway MM (eds) (1998) Comparative psychology: a handbook. Garland, New York, NY

* Grémillet D, Dell'Omo G, Ryan PG, Peters G, Ropert-Coudert Y, Weeks SJ (2004) Offshore diplomacy, or how seabirds mitigate intra-specific competition: a case study based on GPS tracking of Cape gannets from neighbouring colonies. Mar Ecol Prog Ser 268:265-279

* Grémillet D, Lewis S, Drapeau L, van der Lingen CD and others (2008) Spatial match-mismatch in the Benguela upwelling zone: should we expect chlorophyll and sea surface temperature to predict marine predator distributions? J Appl Ecol 45:610-621

Haney JC (1986) Seabird affinities for Gulf Stream frontal eddies: responses of mobile marine consumers to episodic upwelling. J Mar Res 44:361-384

Haraway MM, Maples EG (1998) Species-typical behavior. In: Greenberg G, Haraway MM (eds) Comparative psychology: a handbook. Garland, New York, NY, p 191-197

Hebshi AJ, Duffy DC, Hyrenbach KD (2008) Associations between seabirds and subsurface predators around Oahu, Hawaii. Aquat Biol 4:89-98

Hothorn T, Bretz F, Westfall P (2008) Simultaneous inference in general parametric models. Biom J 50:346-363

James DJ, McAllan IA (2014) The birds of Christmas Island, Indian ocean: A review. Aust Field Ornithol 31:S1-S175

Jaquemet S, Le Corre M, Marsac F, Potier M, Weimerskirch $\mathrm{H}$ (2005) Foraging habitats of the seabird community of Europa Island (Mozambique Channel). Mar Biol 147: 573-582

Jaquemet S, Ternon JF, Kaehler S, Thiebot JB and others (2014) Contrasted structuring effects of mesoscale features on the seabird community in the Mozambique Channel. Deep-Sea Res II 100:200-211

Johnson RL, Venter A, Bester MN, Oosthuizen WH (2006) Seabird predation by white shark and Cape fur seal at Dyer Island. S Afr J Wildl Res 36:23-32

Jovani R, Lascelles B, Garamszegi LZ, Mavor R, Thaxter CB, Oro D (2016) Colony size and foraging range in seabirds. Oikos 125:968-974

Kappes MA, Weimerskirch H, Pinaud D, Le Corre M (2011) Variability of resource partitioning in sympatric tropical boobies. Mar Ecol Prog Ser 441:281-294

Lack DL (1971) Ecological isolation in birds. Harvard University Press, Cambridge, MA

Lance MM, Thompson CW, Burger AE (2005) Overlap in diets and foraging of common murres (Uria aalge) and rhinoceros auklets (Cerorhinca monocerata) after the breeding season. Auk 122:887-901

Le Corre M, Jouventin P (1997) Ecological significance and conservation priorities of Europa Island (western Indian Ocean), with special reference to seabirds. Rev Ecol Terre Vie 52:205-220

KLewis S, Sherratt TN, Hamer KC, Wanless S (2001) Evidence of intra-specific competition for food in a pelagic seabird. Nature 412:816-819

Lewis S, Schreiber EA, Daunt F, Schenk GA, Wanless S, Hamer KC (2004) Flexible foraging patterns under different time constraints in tropical boobies. Anim Behav 68: 1331-1337

Longhurst ARP, Pauly D (1987) Ecology of tropical oceans. Academic Press, San Diego, CA

Lott DF (1991) Intraspecific variation in the social systems of wild vertebrates. Cambridge University Press, New York, NY

Louzao M, Weigand T, Bartumeus F, Weimerskirch H (2014) Coupling instantaneous energy-budget models and behavioural mode analysis to estimate optimal foraging strategy: an example with wandering albatrosses. Mov Ecol 2:8

Marascuilo LA (1966) Large-sample multiple comparisons. Psychol Bull 65:280-290

* Mendez L, Cotté C, Prudor A, Weimerskirch H (2016) Variability in foraging behaviour of red-footed boobies nesting on Europa Island. Acta Oecol 72:87-97

Meyer CG, Papastamatiou YP, Holland KN (2010) A multiple instrument approach to quantifying the movement patterns and habitat use of tiger (Galeocerdo cuvier) and Galapagos sharks (Carcharhinus galapagensis) at French Frigate Shoals, Hawaii. Mar Biol 157:1857-1868

Nel DC, Lutjeharms JRE, Pakhomov EA, Ansorge IJ, Ryan PG, Klages NTW (2001) Exploitation of mesoscale oceanographic features by grey-headed albatross Thalassarche chrysostoma in the southern Indian Ocean. Mar Ecol Prog Ser 217:15-26

Nelson JB (1978) The Sulidae-gannets and boobies. Oxford University Press, Oxford

* Nur N, Jahncke J, Herzog MP, Howar J and others (2011) Where the wild things are: predicting hotspots of seabird aggregations in the California Current System. Ecol Appl 21:2241-2257

\% Oppel S, Beard A, Fox D, Mackley E and others (2015) Foraging distribution of a tropical seabird supports Ashmole's hypothesis of population regulation. Behav Ecol Sociobiol 69:915-926

Orians GH, Pearson NE (1979) On the theory of central place foraging. In: Horn DJ, Stairs GR, Mitchell DR (eds) Analysis of ecological systems. Ohio State University Press, Columbus, OH, p 155-177

*Pante E, Simon-Bouhet B (2013) Marmap: a package for importing, plotting and analyzing bathymetric and topographic data in R. PLOS ONE 8:e73051

* Piontkovski SA, Williams R (1995) Multiscale variability of tropical ocean zooplankton biomass. ICES J Mar Sci 52: 643-656

Pohlert T (2014) The pairwise multiple comparison of mean ranks package (PMCMR). R Package. http://CRAN.Rproject.org/package $=$ PMCMR

R Development Core Team (2014) R: A language and environment for statistical computing. R Foundation for Statistical Computing, Vienna, Austria. http://www.Rproject.org/ 
Redner RA, Walker HF (1984) Mixture densities, maximum likelihood and the EM algorithm. SIAM Rev 26:195-239

Rome MS, Ellis JC (2004) Foraging ecology and interactions between herring gulls and great black-backed gulls in New England. Waterbirds 27:200-210

Schneider D (1982) Fronts and seabird aggregations in the southeastern Bering Sea. Mar Ecol Prog Ser 10:101-103

Schreiber E, Schreiber R, Schenk G (1996) Red-footed booby (Sula sula). In: Poole A, Gill F (eds) The birds of North America, no. 241. The Academy of Natural Sciences, Philadelphia, PA, and The American Ornithologists' Union, Washington, DC, p 1-24

Shealer DA, Schreiber EA, Burger J (2002) Foraging behavior and food of seabirds. In: Schreiber EA, Burger J (eds) Biology of marine birds. CRC Press, Boca Raton, FL, p 137-177

Sims DW, Quayle VA (1998) Selective foraging behaviour of basking sharks on zooplankton in a small-scale front. Nature 393:460-464

Spaggiari J, Barré N, Baudat-Franceschi J, Borsa P (2007) New Caledonian seabirds. In: Payri CE, Richer de Forges $B$ (eds) Compendium of marine species of New Caledonia, 2nd edn. Doc Sci Tech Sér II 7. IRD, Nouméa, p 415-428

Suryan RM, Santora JA, Sydeman WJ (2012) New approach for using remotely sensed chlorophyll a to identify seabird hotspots. Mar Ecol Prog Ser 451:213-225

Tew Kai E, Rossi V, Sudre J, Weimerskirch H and others (2009) Top marine predators track Lagrangian coherent structures. Proc Natl Acad Sci USA 106:8245-8250

Thiers L, Louzao M, Ridoux V, Le Corre M, Jaquemet S, Weimerskirch H (2014) Combining methods to describe important marine habitats for top predators: application to identify biological hotspots in tropical waters. PLOS ONE 9:e115057

Trivelpiece WZ, Trivelpiece SG, Volkman NJ (1987) Ecological segregation of Adélie, gentoo, and chinstrap penguins at King George Island, Antarctica. Ecology 68: 351-361

Wakefield ED, Bodey TW, Bearhop S, Blackburn J and others (2013) Space partitioning without territoriality in gannets. Science 341:68-70

Weimerskirch H (1998) How can a pelagic seabird provision its chick when relying on a distant food resource? Cyclic attendance at the colony, foraging decision and body

Editorial responsibility: Rory Wilson,

Swansea, UK condition in sooty shearwaters. J Anim Ecol 67:99-109

*Weimerskirch H (2007) Are seabirds foraging for unpredictable resources? Deep-Sea Res II 54:211-223

*Weimerskirch H, Bonadonna F, Bailleul F, Mabille G, Dell' Omo G, Lipp HP (2002) GPS tracking of foraging albatrosses. Science 295:1259

WWeimerskirch H, Le Corre M, Jaquemet S, Potier M, Marsac F (2004) Foraging strategy of a top predator in tropical waters: great frigatebirds in the Mozambique Channel. Mar Ecol Prog Ser 275:297-308

* Weimerskirch H, Le Corre M, Jaquemet S, Marsac F (2005a) Foraging strategy of a tropical seabird, the red-footed booby, in a dynamic marine environment. Mar Ecol Prog Ser 288:251-261

* Weimerskirch H, Le Corre M, Ropert-Coudert Y, Kato A, Marsac F (2005b) The three-dimensional flight of redfooted boobies: adaptations to foraging in a tropical environment? Proc R Soc B 272:53-61

Weimerskirch H, Le Corre M, Ropert-Coudert Y, Kato A, Marsac F (2006) Sex-specific foraging behaviour in a seabird with reversed sexual dimorphism: the red-footed booby. Oecologia 146:681-691

*Weimerskirch H, Le Corre M, Bost CA (2008) Foraging strategy of masked boobies from the largest colony in the world: relationship to environmental conditions and fisheries. Mar Ecol Prog Ser 362:291-302

Wilson RP, Pütz K, Peters G, Culik B, Scolaro JA, Charrassin JB, Ropert-Coudert Y (1997) Long-term attachment of transmitting and recording devices to penguins and other seabirds. Wildl Soc Bull 25:101-106

Worton BJ (1989) Kernel methods for estimating the utilization distribution in home-range studies. Ecology 70 : 164-168

*Young HS, Shaffer SA, McCauley DJ, Foley DG, Dirzo R, Block BA (2010) Resource partitioning by species but not sex in sympatric boobies in the central Pacific Ocean. Mar Ecol Prog Ser 403:291-301

*Young HS, Maxwell SM, Conners MG, Shaffer SA (2015) Pelagic marine protected areas protect foraging habitat for multiple breeding seabirds in the central Pacific. Biol Conserv 181:226-235

* Zavalaga CB, Emslie SD, Estela FA, Müller MS, Dell'Omo G, Anderson DJ (2012) Overnight foraging trips by chick rearing Nazca Boobies Sula granti and the risk of attack by predatory fish. Ibis 154:61-73

Submitted: July 25, 2016; Accepted: January 9, 2017

Proofs received from author(s): March 15, 2017 